Interactive comment on "The impact of the ozone effective temperature on satellite validation using the Dobson spectrophotometer network" by M. E. Koukouli et al.

Anonymous Referee \#1

Received and published: 11 February 2016 


\section{The impact of the ozone effective temperature on satellite validation using the Dobson spectrophotometer network}

M. E. Koukouli, M. Zara, C. Lerot, K. Fragkos, D. S. Balis, and M. van Roozendael

February 11, 2016

\section{Summary}

The paper gives a useful evaluation of how the application of the know effective temperature dependence on Dobson spectrometer improves the satellite ground base comparison. The authors validate the $T_{\text {eff }}$ calculations derived from satellite retrieval and with the ECWMF weather model based Temperature profiles with the same a priori climatology used from the satellite retrieval with ozonesonde based derivation.

The improvement of the comparison is clear which suggest to implement an operative implementation for Dobson ozone observations 


\section{Comments}

AMTD

As other referee comment a mention of the different ozone cross section used by satellite retrieval and Brewer /Dobson will be mentioned.

Page 55 Some references are missing on the bibliography (Anton and Labow)

Interactive

comment

Page 725 Can you give more details about the operative analysis used.

Page 810 Do you have an estimation of the bias on $T_{e} f f$ calculated by ozonesondes due the fact of limited altitude of the ozonesonde.

Page 9 10, I think This formula was used from first time by Roozendael 1998 (Formula 4)

Page 1110 : The "know solar zenith angle" dependence should be described and or referenced.

Page 11 10: The brewer comparison are not shown.

Table 1: I suggest to add also the ECWMF vs SONDE stats and include the mean values of the figure 2 .

Figure 2: Plotting the differences to the ozonesonde rather the series could be more illustrative of the comparison.

Figure 5 : The lower panel a description of how the zenith angle and temperature dependence are calculated. 